\title{
ADVANCED RO WATER PURIFIER SYSTEM USING ARDUINO FOR ROADSTER
}

\author{
Ashwini .P . Kharat ${ }^{1}$, Sayali .S . Taralekar ${ }^{2}$, Pradnya .P . Shinde ${ }^{3}$, Parineeta .A . Patil ${ }^{4}$ \\ ${ }^{1}$ B.E, Student, Electronics \& Telecommunication, ADCET, Ashta, Maharashtra, India \\ ${ }^{2}$ B.E. Student, Electronics \& Telecommunication, ADCET, Ashta, Maharashtra, India \\ ${ }^{3}$ B.E. Student, Electronics \& Telecommunication, ADCET, Ashta, Maharashtra, India \\ ${ }^{4}$ B.E, Student, Electronics \& Telecommunication, ADCET, Ashta, Maharashtra, India
}

\begin{abstract}
Water is life so it is very grave. Without water there is no life. Water purification is the technique of eliminating undesirable chemicals, other solids and gases from water. Now a days RO water purifier is used in many applications such as domestic application, railway stations, schools, colleges, hospitals, etc. So this project makes use of purifier system in new application i.e. roadsters. There are many problems faced while travelling in cars/travels like water. We have to purchase water from shops so it become costlier and people through bottles outside i.e. on road so it causes pollution. to overcome these problem a simple $n$ compact $R O$ water system is placed in roadster. This project has large scope. It saves the environment by avoiding use of plastic bottles. It saves the money. No need to purchase water bottles every time while travelling. The water can be reused again for many purposes like roadster wiper, washing roadster.
\end{abstract}

Keywords: Reverse Osmosis, Arduino, Roadster, LM35.

$* * *$

\section{INTRODUCTION}

RO purification is a process for eliminating dust particles and other hazardous materials from water. Reverse Osmosis (RO) is mostly used and accepted water purification process. In Reverse Osmosis, the solvent is moved from high solute to low by using external pressure. This leads to the extraction of dissolved solids making it suitable for drinking . Literature survey of different authors about RO system is explained below.

Propose of this system is o provide drinking water at economic price and high reliability for remote areas and rural families. It includes manufacture of water purification system using renewable energy. This method is portable, cost effective and enough to meet the drinking water needs. This paper is useful for those who are working in the area of water purification system and their use in remote places.[1]

The water filtration techniques in nature $\&$ used for domestic purposes can be combined together \& automated using PLC to create a reliable \& cost-effective system to get clean water. In India most of industries flow waste water or cleaning water into natural fresh resources such as rivers and lakes. When these resources saturate, the quality of water will reduce and downstream water are no longer used. [2]

Increase in water consumption and fresh water resources reduction will cause a water scarcity problem throught world. To overcome problem, there are different methods to produce fresh water from sea water or saline water. Desalination processes have received good solution for fresh water production. This has multistage flash distillation (MSF), multi effect distillation (MED) and vapour compression (VC), which could be mechanical VC. MSF and MED processes consist of stages successfully to decrease temperature and pressure.[3]. Other work has focused to integrate reverse osmosis with electro dialysis to improve recovery of valuable deionized products. The latest developments involves nanoscale and graphene membranes. Water Purification system has two important purification stages, namely Carbon Filtration and Reverse Osmosis (RO).Reverse osmosis (RO) is proved to be reliable, economic and energy efficient to produce fresh water compared to other technologies. Reverse Osmosis plants are a widely used for water treatment engineering all over the world, applied for water conserving projects, emerged by the technology of automation control system .[4]

Currently RO systems are used in homes, industries etc. but while travelling people faces problem related to drinking water. to overcome these problems, designed "Advanced RO water purifier system using Arduino for roadsters"as shown in figure 1. This system can be used in roadsters which contains air conditioner. At the present moment due to befoul of water, distemper disperse at large scale. These distemper may strangle too. Scarcity of water emanate mostly during lingering in cars. To outwit these problems we have publicized RO water purifier system adolf in car. In emergency hot water will be available too. Prestige is that by virtue of air conditioning system present in car we are going to make water hot and cold. So there is no requisite of extra power mandatory for application. 
As the country is making its development through industrialization, our water resources are recumbent to a browbeat of pollution exclusively from the industrial activities.
It is a defy in the enforcement aspect as it is futile for the domination to continuously monitor the venue of water resources due to limitation exclusively in man power, facilities and cost of gadget.

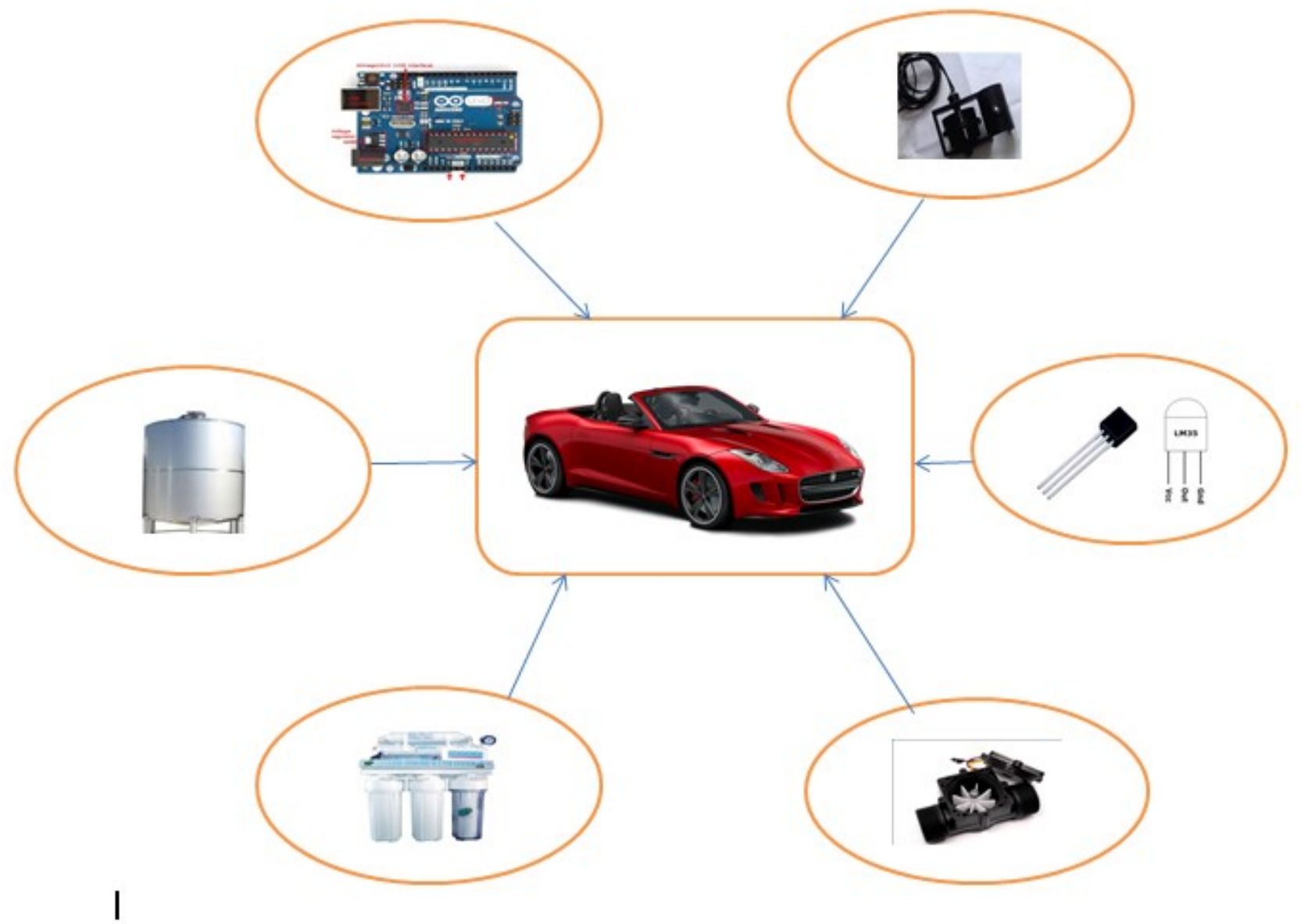

Fig.1:- Advanced system placed in Roadster

\section{PROBLEM DEFINITION}

People can't carry large amount of water in car while travelling. So they purchase water from outside. It becomes costlier.

To minimize these above mentioned problems a simple compact size RO system is designed which can be easily placed at back of car.

\section{METHODOLOGY}

Fig. 2 shows hardware loop diagram. Arduino is the main control unit. All the applications will be controlled by Arduino. Various sensors like temperature, flow and float sensors are controlled by Arduino. In this system Capacitive touch pad is used to control the temperature of water.

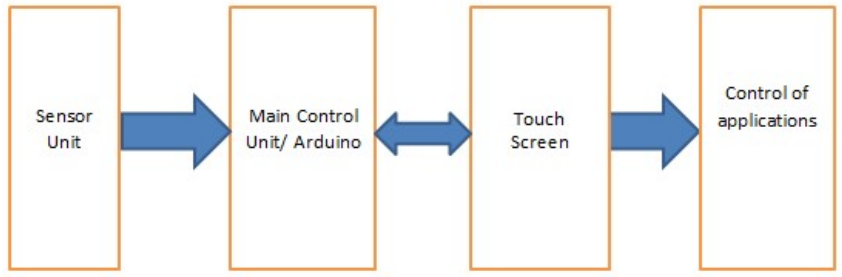

Fig .2:- Hardware Loop Diagram

Figure 3 shows the conceptual diagram of the advanced RO system which is placed in roadster. The main control unit of the system is Arduino Uno microcontroller; it controls the overall units as well as the flow of system. Various parameters like sensor unit, Touch Screen panel, valve control, power supply unit and load control unit are present. Sensor unit consists of three types of sensors: Temperature sensor, Flow sensor, Float sensor. Touch screen panel is used to select to offer normal water and hot water. Power supply unit is used to convert 12 volt power of battery in car to 24 volt power supply. Load control unit consist of Relay. Relay acts as a switch which controls the motor. 


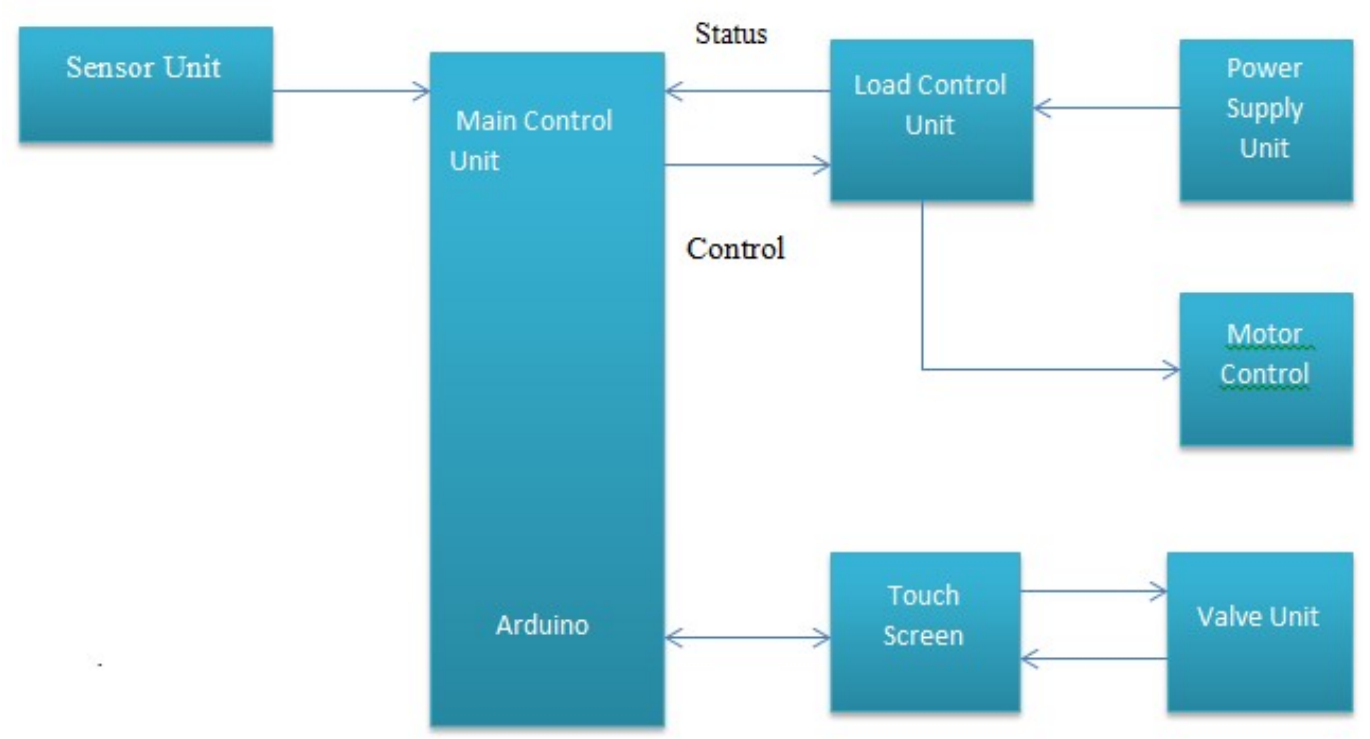

Fig. 3:-Conceptual Block Diagram

\section{APPLICATION}

- This technology can be applied in applications like Cars, Volvos, Trains, Aeroplanes, etc. in which AC system is available.

- In car hot and cold water can be obtained by this system with the use of air conditioner.

\section{CONCLUSION}

As our proposed system is economical, Easy to design and improves standard of living.RO is effective as well as safe. For travelling long distance from roadster there is no need of carrying large number of Water bottles as our proposed system is cost effective. Ro system depends upon efficiency of pre- treatment.

\section{ACKNOWLEDGEMENT}

We would like to express our special thanks to Prof. M.N.Chavan [A.D.C.E.T, ASHTA, MAHARASHTRA, INDIA] for her special guidance and encouragement. We would also like to thanks Mr. Atul Kamble M.E. VLSI \& EMBEDDED SYSTEM, A.D.C.E.T Ashta] for his advice which helped us for writing this review paper.

\section{REFERENCES}

[1]. S.S.Phuse, R.S.Shelke. "Water Purification System For Remote Areas Using Photovoltaics". International Journal of Engineering Research and Applications (IJERA) . Vol. 2, Issue4, July-August 2012.

[2]. Piyush R. Panditrao and et al. "Cost Effective Automated Water Filtration and Recycling System". International Journal of Advanced Research in Electrical, Electronics and Instrumentation Engineering Vol. 3, Issue 1, January 2014"

[3]. B. Sri Hari Priya and et al. "Review on Water Desalination using Renewable Solar Energy". International Journal for Innovative Research in Science \& Technology| Volume 2 | Issue 07 | December 2015.
[4]. Raviteja Chintala and Nitin Padhiyar. "Experimental Study on Reverse Osmosis System with Carbon Nano Tubes from Candle Soot". International Journal of Chemistry and Chemical Engineering. Volume 3, Number 3, 2013.

\section{BIOGRAPHIES}

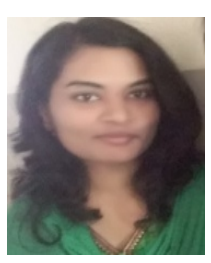

Ashwini .P. Kharat, [B.E Electronics \& telecommunication]ADCET,ASHTA

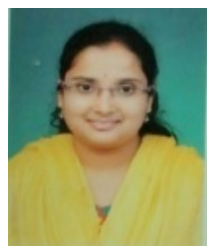

Sayali. S . Taralekar, [B.E Electronics \& telecommunication]ADCET,ASHTA

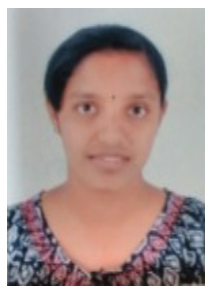

Pradnya .P . Shinde, [B.E Electronics \& telecommunication]ADCET,ASHTA

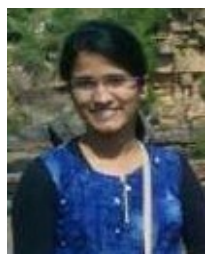

Parineeta .A. Patil, [B.E Electronics \& telecommunication]ADCET,ASHTA 